\title{
Clinical Implications of Regressive Alterations of Teeth and their Management
}

\author{
Harshitha Alva, Krishna Prasad D, Manoj Shetty, Vinaya Bhat \\ Department of Prosthodontics, AB Shetty Memorial Institute of Dental Sciences, Mangalore, Karnataka, India
}

\begin{abstract}
Correspondence: Harshitha Alva, Department of Prosthodontics, AB Shetty Memorial Institute of Dental Sciences, Mangalore Karnataka, India, e-mail: drharshitha@gmail.com

\section{ABSTRACT}

Regressive alteration is a multifactorial condition causing loss of enamel and dentine. The cause is generally erosion, abrasion, abfraction, attrition and resorption or a combination of these lesions. Progression of regressive changes is found to be slow with periods of activity and inactivity. Although restorations are indicated, prevention remains the prime strategy in maintaining the longevity of a tooth. A thorough knowledge of the etiology, signs and symptoms of these lesions is of utmost importance in the diagnosis and management.

Conclusion and clinical implications: This article describes the etiological factors and assists the readers in reaching a diagnosis on the type of lesion and their appropriate management.

Abbreviations: NCCL: Noncarious cervical lesion; VDO: Vertical dimension at occlusion; RMGIC: Resin-modified glass ionomer cement.

Keywords: Erosion, Abrasion, Abfraction, Attrition.
\end{abstract}

\section{INTRODUCTION}

Regressive changes are a group of retrogressive changes of teeth which occur due to nonbacterial causes resulting in wear and tear of tooth structures with impairment of function. Studies ${ }^{1-12}$ on the mechanism of stress concentration in cervical areas concluded that occlusal loading forces result in tooth flexures which lead to mechanical microfractures and loss of tooth structure in the cervical areas. This loss was termed them as abfraction.

Few investigators ${ }^{6-8,10}$ have concluded that the cause of non carious cervical lesions (NCCLs) could be acid in areas of stress concentration which results in either static or cyclic stress corrosion.

Although, tooth wear to a certain extent is accepted as a part of the normal aging process, problems associated with tooth wear are of concern. A dental survey on middle-aged adults showed an increase in the rate of tooth wear with age on the cervical, occlusal and incisal surfaces and studies on young adults reported that prevalence of tooth wear was in the range of 6 to $45 \%$. ${ }^{13,14}$

The regressive changes of prosthetic concern involve attrition, abrasion, erosion, abfraction and resorption. Diagnosis and management of these regressive alterations of teeth is essential for long-term functionality of the stomatognathic system as well as for the comfort of the patient.

\section{Attrition}

The term attrition was derived from the Latin verb attritium which describes the action of rubbing against something. Tooth wear produces well-defined wear facets on the functional surfaces of the teeth. A ttrition could be attributed by factors like abnormal occlusion, abnormal chewing habits, developmental defects, diet or opposing restoration. ${ }^{14}$ It was postulated that though cupping of incisal edges could be due to acid attack or due to abrasion as dentine exhibits lower wear and erosion resistance than enamel. ${ }^{15} \mathrm{~A}$ trition over the proximal surfaces of teeth leads to shortening of the dental arch.

Radiographic view reveals shortened crown image, sclerosis of the pulp chambers and the canals due to deposition of secondary dentine, widening of the periodontal ligament space, hypercementosis and loss of alveolar bone might also occur. $^{16}$

\section{Abrasion}

A brasion is pathological wearing away of tooth substance due to abnormal mechanical process. ${ }^{16}$ The causes of abrasion are improper brushing technique, use of abrasive dentifrices, improper use of toothpicks and dental floss, biting on hard objects like pins or finger nails, etc. ${ }^{17}$ The lesion presents with V-shaped or wedge-shaped notches at the cervical margins.

Studies have concluded that wear depends on the tooth alignment and which hand is holding the toothbrush-more facets occur on the left side of a right-handed person and vice versa. ${ }^{14}$ Tooth wear caused due to friction by food bolus was termed as masticatory abrasion. ${ }^{17}$

Radiographic view shows radiolucent defect at the cervical level and partial or full sclerosis of pulp chamber in case of toothbrush injury and narrow semilunar grooves in the interproximal surfaces of the teeth near the cervical area in dental floss injury. ${ }^{16}$

\section{Erosion}

Erosion is the loss of tooth structure by a chemical process that does not involve a known bacterial action. Erosion may be 
caused due to intrinsic (gastroesophageal reflux, vomiting) or extrinsic acids (acidic beverages, citrus fruits) and modified by salivary flow rates and its constituents. ${ }^{14} \mathrm{~L}$ abial and buccal surfaces of the teeth are involved and the lesion is smooth with no chal kiness. Perimolysis is erosion marked on palatal surfaces of maxillary anterior teeth is caused due to forcefully directed movement of vomitus which has a mean $\mathrm{pH}$ of $3.8 .^{18}$

$\mathrm{H}$ aw den ${ }^{19}$ described a particular pattern of tooth structure loss in patients with gastrointestinal reflux disease. He reported the enamel appears thin and translucent and that enamel is lost on occlusal surfaces of posterior and palatal surface of anterior teeth because of wear. This cupping resulted due to the combined action of hydrochloric acid and proteolytic enzyme pepsin contained in digestive juice. ${ }^{17}$

A study by Hughes reported that the concentration, type and the duration of exposure to dietary acids influence the extent of erosion. ${ }^{20}$ E ccles stated that the major etiological factor was acidic beverages in $40 \%$ of patients with anterior tooth wear. ${ }^{21}$

A ccording to Bodecker, gingival crevicular fluid is also acidic and may be corrosive on the cervical areas, when in contact with the tooth. ${ }^{17}$ Dental erosion varied with drinking methods such as holding the drink longer in the mouth lead to a more pronounced $\mathrm{pH}$ drop. It has been reported that food with $\mathrm{pH}$ less than 5.5, act as a corrodent and demineralize the teeth. ${ }^{22-24}$ Carbonated beverages are cited as a cause of tooth decalcification and their corrosive effect was found to be due to added citric and phosphoric acid. ${ }^{25-28}$ D rinking with an increasing flow rate and with decreasing outl et diameter could increase the erosion depth. The effect is al so strengthened when acid temperature grows higher.

A ccording to V irrette, ${ }^{29}$ corrosion on occlusal surface of posterior teeth could be attributed to chewable vitamin $C$ tablets, ${ }^{30}$ aspirin tablets and pow der, ${ }^{31,32}$ and amphetamine drug ecstasy. ${ }^{33}$ Alcohol abuse has also been suggested to cause corrosion due to chronic regurgitation and vomiting. ${ }^{34,35}$

Radiographic imaging shows a radiolucent defect on the crown margins which may be diffuse or well defined.

\section{Abfraction}

A Iso called as stress lesion, is a consequence of eccentric forces on the natural dentition. The term 'abfraction' was coined from the $L$ atin w ords ab meaning aw ay and fractio meaning breaking. A bfraction implies the pathologic loss of tooth structure attributed to mechanical loading and resulting in wedge-shaped defects in the cervical areas. This is due to breaking away of thin layer of enamel rods as well as cementum and dentin. 3,4 Stresses that concentrate to produce abfractions usually are transmitted by occlusal loading forces. ${ }^{3-5}$ A $n$ abfraction lesion should be located at or near the ful crum in the region of greatest tensile stress concentration, be typically wedge-shaped, and display a size proportional to the magnitude and frequency of tensile force application. ${ }^{36}$

K ornfield stated that cervical lesion occurs on that part of the tooth that opposes the side that has developed an occlusal wear facet by attrition. ${ }^{37}$

\section{Resorption}

Resorption is chronic progressive damage or loss of tooth structure due to the action of cells called odontoclasts. Resorption can be either physiological that is seen in deciduous teeth or it can be pathological seen in permanent dentition. Pathological resorption can be external or internal.

In external resorption the affected tooth is usually asymptomatic. M ost frequently the maxillary incisors, maxillary and mandibular bicuspids are involved. When the root is resorbed, the tooth may become mobile but, if resorption is followed by ankylosis then tooth will be immobile. Roentograms show smooth resorption of the root surface. The conical end is removed and replaced by more or less blunt or usually square apex. ${ }^{16}$

Internal resorption is a condition starting in the pulp chamber and expands by resorption of the surrounding dentin. Teeth presents with a pink hued area within the pulp which represents hyperplastic pulp tissue fitting the resorbed area and showing through the overlying tooth substance. Radiographically, the lesion is radiolucent, round, oval el ongated within the root with widening of the pulp chamber and the canals. Internally, radiolucency is homogeneous without bony trabeculation or radiopaque foci.

\section{DISCUSSION}

The regressive changes of teeth involve biologic, functional and esthetic implications. Biologic implications involve loss of tooth substance producing irregular tooth surface enhancing plaque retention, pulpal exposure and inturn weakening the tooth structure. Loss of tooth substance cannot always be compensated by continuous eruption. Hence, there is undoubtedly certain degree of loss of masticatory efficiency. Esthetics is always comprised when there is a loss of tooth structure.

Some authors suggest that tensile and compressive stresses play a primary rolein causing enamel and dentin fracture, while abrasion and erosion have been found to play secondary role. A number of controversies surround the topic of tooth wear. Some of them being whether to raise the vertical dimension or not, when to start treatment, what is the role of occlusion, what is the best material to use, and when is wear pathologic and when physiologic.

It is always mandatory to evaluate the vertical dimension before restoration. The different techniques that can be implemented include the use of interocclusal distance, phonetics or even evaluation of soft tissue esthetics. Correlations were found between attrition and anterior space relationships. A bsence of posterior teeth did not always lead to excessive attrition of remaining teeth but increased wear was always associated with decreased number of teeth. ${ }^{38}$ There were no correlations found between attrition and other occlusal parameters. ${ }^{38}$ The most preferred material of choice is resin based composites, glass ionomers or a combination. Others include metal restorations for posterior teeth, dentin bonding 
agents, dietary modifications, night guard and occlusal adjustments. ${ }^{39}$

The decision on whether to restore a worn dentition or not al ways depends on the severity, potential for progression and most importantly the patients need. A classification as mild, moderate and severe can help us in deciding on the treatment. $M$ ild tooth wear is one involving less than $1 / 3$ tooth surface (dentine exposure) and do not require any treatment. M oderate wear involves al most $2 / 3$ the tooth surface, requires treatment and depends on what the patient needs. M oderately worn tooth can be monitored for some time and does not al ways demand treatment. Severe wear involves secondary dentine exposure and loss of tooth height. The level of wear dictates the treatment. ${ }^{40}$

\section{Prosthetic Implications and Management}

Dentoalveolar compensation causes the OVD (occlusal vertical dimension) to remain relatively constant or even increased, despite the tooth wear. Decrease in tooth height is compensated by deposition of secondary cementum around root apices of the involved teeth and increase in tooth height is compensated by regressive remodeling of the dentoalveolar process, or by intrusion into the alveolus.

Turner and M issirlian classified tooth wear as: ${ }^{41}$

- Category 1: Excessive wear with loss of VDO.

- Category 2: Excessive wear without loss of VDO but with space available.

- Category 3: Excessive wear without loss of VDO but with limited space.

$M$ anagement of attrition involves the use of splints like the soft bite guard, localized occlusal interference splint, stabilization splint and night guards. From a prosthetic point view, attrition is of particular concern because it interacts directly with a central issue occlusion. A ssociation between attrition and anterior relationship has been reported in several studies. A nterior guidance seems to reduce the risk for posterior attrition but increases the risk of anterior attrition.

B ruxism has been identified as an associated factor in attrition. ${ }^{42} \mathrm{~A}$ discrepancy between centric relation and centric occlusion was the most common trigger for muscle spasms, bruxism and dysfunctional temporomandibular joint disturbances. Restriction of the anterior guidance, almost without exception produces excessive attritional wear on the restricting surfaces. Furthermore, correction of the restricted anterior guidance almost al ways eliminates the wear problem and by perfecting the occlusion of a bruxer, full muscle load occurs in centric relation when all parts are al igned. Immediate disocclusion of all posterior teeth eliminates any potential overload in eccentric positions and it reduces muscle loading of the joint and the anterior teeth. ${ }^{43}$

$N$ oncarious loss of tooth structure demands treatment for reasons of sensitivity, esthetics, function and loss of interocclusal space. From the prosthetic perspective, managing the loss of interocclusal space involves occlusal reduction, surgical crown lengthening, and arbitrary increase of VD, orthodontic therapy or a Dahl bite raising appliance. ${ }^{44}$
For a patient whose tooth surface loss is essentially caused by erosive fluids, advice regarding diet, use of sugar-free gums, saliva substitutes containing calcium and phosphate are relevant to remineral ize erosively al tered enamel and dentin. Evidences state that fluorides are effective in erosion and abrasion by hardening the tooth structure and increasing the resistance to dissolution..$^{45}$

If the wear is primarily caused by abrasion then examination and modification of the tooth cleaning habits are required. ${ }^{46} \mathrm{M}$ anagement of abrasive lesion involves restoring the lesion with glass ionomer cements (GICs), resin-modified GICs (RM GICs), a GIC/RM GIC liner / base laminated with a resin composite, and resin composite in combination with a dentine bonding agent are all restorative options. RM GIC should be the first preference in esthetically demanding cases, a RM GIC/GIC liner / base be laminated with resin composite.

If a tooth with a cervical lesion was to be used as an abutment for a fixed prosthesis, it requires to be restored initially. If the lesion is superficial, restoration involves the use of any of the cements or if lesion is severe endodontic procedures should be followed. During the tooth preparation, the finish line should lie apical to the lesion. For esthetic reasons to mask the increase in clinical crown length due to apical margins, either grafts or gingival porcelains can be used.

Resorption needs to be considered when restoration involves fixed prosthodontics therapy as it may alter the crown root ratio and result in poor prognosis of the prosthesis.

\section{SUMMARY AND CONCLUSION}

This article describes the etiology, diagnosis, clinical implications and the effective management of tooth wear. These regressive changes of teeth are not reversible, how ever they can be managed and further progression can be prevented. Hence, the prime concern should al ways be to correctly identify the signs of a worn dentition and then using an orderly evaluation process, arrive at an understanding of the etiology and then plan the treatment protocol accordingly, only then can a dental surgeon restore the patients function and esthetics accurately.

\section{REFERENCES}

1. L ebau GI. The primary cause and prevention of dental caries. Bull U nion Cty Dent Soc 1968;47(5):11-13.

2. L ebau GI. The primary cause and prevention of dental caries. Bull Union Cty Dent Soc 1968;47(6):13-16.

3. M CCoy G. On the Iongevity of teeth. J Oral Implantol $1983 ; 11(2): 248-67$.

4. Lee WC, EakleW S. Possible role of tensile stress in the etiology of cervical erosive lesions of teeth. J Prosthet Dent 1984; 52(3):374-80.

5. Lee WC, Eakle WS. Stress-induced cervical lesions: Review of advances in the past 10 years. J Prosthet Dent 1996;75(5): 487-94.

6. Grippo J O, M asi JV. Role of biodental engineering factors (BEF) in the etiology of root caries. J Esthet Dent 1991;3(2):71-76. 
Clinical Implications of Regressive Alterations of Teeth and their Management

7. K han F, Y oung W G, Shahabi S, Daley TJ. Dental cervical lesions associated with occlusal erosion and attrition. A ust D ent J 1999;44(3):176-86.

8. Whitehead SA, Wilson NHF, Watts DC. Development of noncarious cervical notch lesion in vitro. J Esthet Dent 2000;11:332-37.

9. Pintado MR, DeL ong R, Ko C, Sakaguchi RL, Douglas WH. Correlation of noncarious cervical lesion size and occlusal wear in a single adult over a 14-year time span. J Prosthet Dent 2000;84:436-43.

10. Palamara D, Palamara JE, Tyas MJ, Pintado M, M esser HH. Effect of stress on acid dissolution of enamel. Dent $M$ ater 2001;17(2):109-15.

11. Haines KJ, B erry DC, Poole DF. B ehavior of tooth enamel under load. J Dent Res 1963;42:885-88.

12. Lehman $M L$, M eyers $M L$. Relationship of dental caries and stress: Concentrations in teeth as reveal ed by photoelastic tests. J Dent Res 1966;45:1706-14.

13. Grippo J0. Abfractions. A new classification of hard tissue lesions of teeth. J Esthet Dent 1991;3(1):14-19.

14. Chu FC, Y ip HK, N ewsome PR, Chow TW, Smales RJ. Restorative management of worn dentition: 1. A etiology and diagnosis. Dent U pdate 2002;29(4):162-68.

15. Mair LH, Stolarski TA, Vowles RW, Lioyd CH. Wear: $M$ echanisms, manifestations and measurement.

16. Ghom AG. Textbook of oral medicine: J aypee 453-62.

17. Grippo J O, Simring M, Schreiner S. Attrition, abrasion, corrosion and abfraction revisited: A new perspective on tooth surface lesions. J A m Dent A ssoc 2004;135(8):1109-18.

18. M ilosevic A, B rodie DA, Slade PD. Dental erosion, oral hygiene, and nutrition in eating disorders. Int J Eat Disord 1997;21(2): 195-99.

19. Howden GF. Erosion as the representing symptom in hiatus hernia: A case report. Br Dent J 1971;131:455-56.

20. Pepsin. The new encyclopedia B ritannica, micropedia ready reference. Chicago: Encyclopedia B ritannica; 2003;5:141-55.

21. Towle A. M odern biology. A ustin, Texas: Holt, Rinehart and Winston 1999:986.

22. Stephan RM. Changes in the hydrogen ion concentration on tooth surfaces and in carious lesions. JA DA 1940;27:718-23.

23. Gray JA. K inetics of the dissolution of human dental enamel in acid. J Dent Res 1962;412:633-45.

24. Zero DT. Cariology. Dent Clin N orth A m 1999;43(4):655.

25. Imfeld $T$, et al. Dental erosion. Definition, classification and links. Eur J Oral Sci 1996.

26. Linkosalo $E, M$ arkkanen $H$. Dental erosions in relation to lactovegetarian diet. Scand J Dent Res 1985;93:436-41.

27. Lussi A. Dental erosion: Clinical diagnosis and case history taking. Eur J Oral Sci 1996;104(2 Pt 2):191-98.

28. Ten Cate JM, Imfeld T. Dental erosion, summary. Eur J Oral Sci 1996;104:241-44.
29. V errett RG. A nalyzing the etiology of an extremely worn dentition. J Prosthodont 2001;10:224-33.

30. Giunta JL. Dental erosion resulting from chewable vitamin C tablets. J A m Dent A ssoc 1983;107:253-56.

31. Sullivan RE, K ramer W S. Iatrogenic erosion of teeth. ASDC J Dent Child 1983;50(3):190-96. Cited in: Verrett RG . A nalyzing the etiology of an extremely worn dentition. J Prosthodont 2001;10:224-33.

32. $\mathrm{M}$ cC racken $\mathrm{M}, \mathrm{O}^{\prime} \mathrm{N}$ eal $\mathrm{S}$ ] . Dental erosion and aspirin headache powders: A clinical report. J Prosthodont 2000;9(2):95-98. Cited in: Verrett RG. A nalyzing the etiology of an extremely worn dentition. J Prosthodont 2001;10:224-33.

33. Redfearn PJ, A grawal N, M air L H. A n association between the regular use of 3,4 methylenedioxy-methamphetamine (ecstasy) and excessive wear of the teeth. A ddiction 1998;93:745-48. Cited in: Verrett RG. A nalyzing the etiology of an extremely worn dentition. J Prosthodont 2001;10:224-33.

34. Christen A G. Dentistry and the alcoholic patient. Dent Clin N orth Am 1983;27:341-61.

35. Robb ND, Smith BG. Prevalence of pathological tooth wear in patients with chronic al coholism. Br Dent J 1990;169:367-69.

36. M ichael JA, Townsend GC, Greenwood LF, K aidonis JA. A bfraction: Separating fact from fiction. A ust D ent J $2009 \mathrm{M}$ ar; 54(1):2-8.

37. Bird CK. Erosion and abrasion of natural teeth. The remedy or correlation of these conditions. Dent Cosmos 1931;7(3):1,204-08.

38. V an 't Spijker A, K reulen CM, Creugers NH. A ttrition, occlusion, (dys) function, and intervention: A systematic review. Clin Oral Implants Res J un 2007;18(Suppl 3):117-26.

39. Litonjua LA, A ndreana S, Bush PJ, Tobias TS, Cohen RE. Noncarious cervical lesions and abfractions: A re-evaluation. J Am Dent A ssoc Jul 2003;134(7):845-50.

40. David W B arttlett. The role of erosion in tooth wear: A etiology, prevention and management. International Dental Journal 2005;55:277-84.

41. Turner K A, M issirlian DM. Restoration of the extremely worn dentition. J Prosthet Dent Oct 1984;52(4):467-74.

42. Hobkirk JA. Tooth surface loss: Causes and effects. Int J Prosthodont J ul-A ug 2007;20(4):340-41.

43. Ramfjord SP. Dysfunctional temporomandibular joint and muscle pain. J Prosthet Dent 1961;11(2):353-74.

44. Poyser NJ, Porter RW, Briggs PF, Chana HS, Kelleher M G. The Dahl Concept: Past, present and future. Br D ent J J un 2005; 198(11):669-76.

45. Bartlett DW. The role of erosion in tooth wear: A etiology, prevention and management. Int Dent J 2005;55(4 Suppl 1): 277-84.

46. Davies SJ, Gray RJ, Qualtrough AJ. M anagement of tooth surface loss. Br Dent J 12 Jan, 2002;192(1):11-6, 19-23. 